\title{
PRODUCTIVITY MEASUREMENT WITH NATURAL CAPITAL
}

\author{
BY \\ NICOLA BRANDT \\ Economics Department, OECD \\ PAUL SCHREYER* \\ Statistics Department, OECD \\ VERA ZIPPERER \\ Economics Department, OECD
}

October 2014

\begin{abstract}
This paper proposes a measurement framework that explicitly accounts for the role of natural capital in productivity measurement. It is applied to aggregate economy data from the OECD Productivity Database, with natural capital data from the World Bank. It is shown that the direction of the adjustment to productivity growth depends on the rate of change of natural capital extraction relative to the rate of change of other inputs. The extended framework also makes the contribution of natural capital to economic growth explicit. This can be useful for countries relying on non-renewable resources to better understand the need to develop other sources of growth - human or productive capital - to prepare for times of scarcer resource endowments. The framework can readily be applied to more encompassing natural capital data, once it becomes available.
\end{abstract}

JEL Codes: D24, Q56, Q50

Keywords: environmental efficiency, green productivity, multi-factor productivity, natural capital stock, natural resource accounting

Note: The authors owe thanks to Francisco M. Guillen from the Instituto Nacional de Estadistica y Geografia of Mexico for providing data on produced capital stocks for Mexico and Ilya B. Voskoboynikov for providing productivity data for Russia. The authors would also like to thank Paul O'Brien, Artur Radziwill and participants of OECD seminars for their useful comments and suggestions, Erwin Diewert for his discussion and comments at the IARIW-UNSW Conference in Sydney, December 2013, as well as two anonymous referees. The opinions expressed herein are those of the authors and do not necessarily reflect the opinions of the OECD or its Member countries. This research has been possible thanks to financial support from the Norwegian Government.

*Correspondence to: Paul Schreyer, Organisation for Economic Co-operation and Development (OECD), 2, Rue André Pascal, 75775 Paris CEDEX 16, France (Paul.Schreyer@ oecd.org) 


\section{Introduction}

Common measures of economic performance do not fully account for the role of the environment in production. While income generated through the depletion of natural capital, such as minerals and fossil fuels, is captured in the value of Gross Domestic Product (GDP) and in profits, the role of natural capital as an input factor is generally ignored in traditional Multi-Factor Productivity (MFP) growth measures. The typical production function used in productivity analysis includes labour and produced capital as input factors, but not natural capital, although the extraction of subsoil assets contributes a considerable share to GDP in some countries.

Recognising natural capital as an input may change measured productivity growth and the assessment of the sources of economic growth. In addition, an explicit analysis of the role of natural capital in production is an important element to better understand the sustainability of economic development. Depleting natural capital often leads to higher economic growth in the short term, but this can only be sustained if a sufficient part of the associated revenues is used to build other assets, such as human or physical capital, to secure the economy's ability to generate income in the long run. To assess this ability it is important to measure the use of natural capital in production, such as fossil fuels and minerals, along with produced capital such as infrastructure, machines and buildings. Measuring the growth contribution of natural capital provides a clearer idea about the extent to which the growth contribution of other production factors or productivity growth would have to increase to maintain similar levels of output growth when the natural capital stock declines and hence also the possibility to use it in production.

It is important to note that the extended productivity growth measure presented in this paper accounts only for the use of domestic natural capital, not for an economy's contribution to the global depletion of natural capital. This is because the interest of the analysis in this paper lies in better understanding the role of natural capital for traditional MFP growth measures at the aggregate economy level. This measure typically subtracts changes in labour and produced capital inputs from GDP growth. Since GDP measures value added, it does not include the value of imported natural capital, which is an intermediate good. Consequently, it would not be correct to consider imported natural capital as an input to the production of GDP. Only the income generated by extracting domestic natural capital, such as oil or minerals, contributes to GDP, and thus only domestic natural capital can be considered an input factor.

Natural capital in this study is valued with its private user cost to companies that extract natural capital or use it in other ways to generate income. It is thus treated like labour and produced capital in the analysis. The question being addressed is the efficiency with which producers use labour, produced and natural capital to generate income, given the prices which they face. In particular, prices do not necessarily reflect the social cost of using natural capital, which may be much larger in some cases. Given the importance of forests for biodiversity, climate stability, soil integrity and as a source of medication, the social value of living trees is likely to be much larger than the market price of their wood. The loss of this value that results from logging is thus not fully captured by the productivity data presented here. The productivity growth measure presented in this paper is in no way a measure of welfare. It is a measure of efficiency with which producers in the economy transform inputs into outputs given the prices that they face.

This paper is organised as follows. The first section spells out a production framework that integrates the use of natural capital in production, and describes the data. Section 2 presents empirical results. Section 3 draws conclusions and suggests possibilities to extend this research. 


\section{A framework including the use of natural capital in productivity growth measurement}

Productivity growth is typically measured as the difference between output growth and the growth in factor inputs. Traditional measurement of MFP within the Solow residual framework is based on a production function that combines inputs from labour, L, and produced (as opposed to natural, nonproduced) capital, $\mathrm{K}$, to generate output. Typically, when measuring productivity for the aggregate economy, the output measure is real GDP, denoted by $\mathrm{Y}$ in what follows. The production process is thus described by $Y=f(K, L, t)$, where $t$ is an index of time. Productivity growth is defined as the shift of the production function over time, allowing producers to obtain more output with the same amount of inputs. Productivity growth is equivalent to the difference between output and aggregate input growth. Weights for the growth of labour and produced capital correspond to their respective cost shares if producers maximize profits (or minimize costs) (see Appendix 1; for an overview of the theory underlying productivity measurement see OECD, 2001; Diewert and Nakamura, 2007; Jorgenson, 1995). Productivity growth can hence be described by the following equation:

$\frac{d \ln M F P}{d t} \equiv \frac{\partial \ln f}{\partial t}=\frac{d \ln Y}{d t}-\left(\frac{w L}{\gamma^{\prime}} \frac{d \ln L}{d t}+\frac{u_{K} K}{\gamma^{\prime}} \frac{d \ln K}{d t}\right)$

where $\frac{d \ln X}{d t}$ denotes the logarithmic rate of change of variable $X$ with respect to time, equivalent to its growth rate, $\mathrm{w}$ is the wage rate and $u_{K}$ the user cost of produced capital. Total resource costs are defined by $\gamma^{\prime} \equiv \mathrm{wL}+\mathrm{u}_{\mathrm{K}} \mathrm{K}$. In what follows, the shorthand $\frac{\mathrm{dlnZ}}{\mathrm{dt}}$ will be used to capture the combined rate of growth of inputs: $\frac{\mathrm{d} \operatorname{lnZ}}{\mathrm{dt}} \equiv\left(\frac{\mathrm{wL}}{\gamma^{\prime}} \frac{\mathrm{dln} \mathrm{L}}{\mathrm{dt}}+\frac{\mathrm{u}_{\mathrm{K}} \mathrm{K}}{\gamma^{\prime}} \frac{\mathrm{dln} \mathrm{l}}{\mathrm{dt}}\right)$.

While there are other ways to measure productivity growth, such as data envelopment analysis, parametric methods or econometric methods, the main interest of this paper lies in better understanding the effect of including natural capital into the traditional MFP measure, as this is frequently used for the analysis of economic growth and productivity at the aggregate economy level. Such measures are readily available in the OECD Productivity Database ${ }^{1}$ and can be relatively easily extended to demonstrate the effect of integrating natural capital into traditional productivity measurement. It is important to understand to which extent commonly used productivity growth measures can change, once natural capital is included in the analysis.

Including natural capital into this framework requires an adjustment of the aggregate input measure. The input index is extended to include natural capital. The flow of natural capital inputs, such as minerals, oil, gas and coal, will be denoted by $S$, the vector of quantities of natural capital inputs, $S=\left(S_{1}, \ldots, S_{i}, \ldots, S_{N}\right)$, that are used in production. Through the inclusion of $\mathrm{S}$, the role of natural capital is explicitly taken into account. As in the traditional framework, productivity growth can be measured as the difference of the growth rates of output and aggregate inputs. However, the set of inputs will now be augmented by the natural capital input $\mathrm{S}$. It should be noted that natural capital input is measured differently from produced capital input. While it is relatively easy to measure the flow of natural capital services as the volume of natural capital extraction, the services of produced capital, such as machines and buildings, are more difficult to observe and the service flow of each type of asset is assumed to be proportional to the produced

\footnotetext{
${ }^{1}$ The scope of assets in the OECD Productivity database is limited to non-residential fixed assets. Consequently, land - another important non-produced asset along with subsoil resources - is not covered by the database nor by the traditional MFP measures. Inclusion or exclusion of land can modify measured capital input and MFP. Typically, the inclusion of land will lead to a reduction in the growth rate of overall capital input and consequently to an increase in measured TFP. For an empirical example, see Cho, Kim and Schreyer (2014).
} 
capital stock. This implies that, for each type of asset, the rate of change of capital services equals the rate of change of the capital stock. Capital services for all assets then enter the productivity calculations as the rate of change of the stock of different asset classes weighted by their user cost shares (OECD, 2009), which add up to the rate of change of the aggregate capital services measure, K. User cost weighting captures the marginal productivity of each type of capital service. Natural capital, in contrast, enters the productivity calculations directly as a flow measure, that is annual extraction of each natural asset.

To build an aggregate input growth measure, a price for natural capital inputs is needed. The (private) user costs for using natural capital is denoted by $u_{S}$, which may be explicit, such as license fees for exploiting a mine or using a stream to run a hydropower station, or implicit if the producer is an owneruser of a natural capital stock. In that case, $u_{S}$ would be the private shadow price of using natural capital in production, or the reduction in the value of the natural capital stock that results from extracting one (further) unit of it. Appendix 2 discusses the conditions under which $u_{S}$ is equivalent to the unit rent of natural capital input. $\mathrm{S}$ should be thought of as an aggregate of different types of natural capital inputs $\mathrm{S}_{\mathrm{i}}$ $(\mathrm{i}=1,2, .$.$) with user costs u_{S_{i}}$. Total input costs, $\gamma$, including natural capital, are defined by $\gamma \equiv w L+$ $u_{K} K+\sum_{i} u_{S_{i}} S_{i}$. The productivity growth measure then becomes (see Appendix 1 for a derivation):

$\frac{d \ln G M F P}{d t}=\frac{d \ln Y}{d t}-\left(\frac{w L}{\gamma} \frac{d \ln L}{d t}+\frac{u_{K} K}{\gamma} \frac{d \ln K}{d t}+\sum_{i} \frac{u_{S_{i}} S_{i}}{\gamma} \frac{d \ln S_{i}}{d t}\right)$

In practice, MFP growth with or without natural capital is measured as a Törnqvist index, which is an approximation of equations (1) and (2) in discrete time version, as explained in more detail on Appendix 1 and 3.

Whenever it is available, MFP data is taken from the OECD Productivity Database, where the user cost of capital is derived 'exogenously' from estimates of its elements, namely the long-run rate of return, the depreciation rate and the price of investment goods (OECD, 2009). This user cost estimate multiplied by the capital stock, corresponds to the cost of capital services, which, together with labour costs, make up total costs $\gamma^{\prime} \equiv w L+u_{K} K$ in the traditional framework. In the extended framework with natural capital, costs are considered to be larger, including also the costs of services from natural capital, $\gamma \equiv w L+$ $u_{K} K+\sum_{i} u_{S_{i}} S_{i}$. The cost shares of both labour and capital will have to be scaled down to reflect the increase in total costs, when the traditional measure is adjusted to include natural capital. It can be shown that the difference between the growth in $\mathrm{S}$ and growth in the traditional input index, $\mathrm{Z}$, comprising labour and capital, determines whether traditional MFP growth has to be adjusted upwards or downwards (Appendix 1).

$\frac{d \ln G M F P}{d t}=\frac{d \ln M F P}{d t}+\sum_{i} \frac{u_{S_{i}} S_{i}}{\gamma}\left(\frac{d \ln Z}{d t}-\frac{d \ln S_{i}}{d t}\right)$

As there is no need to make any assumption regarding returns to scale or the degree of competitiveness of output markets to derive the MFP growth measure presented in the OECD Productivity Database, total $\operatorname{costs} \gamma^{\prime}$ do not necessarily equal the value of GDP in this framework. Typically costs $\gamma^{\prime}$ are smaller than nominal GDP. One interpretation, which suits the extended framework with natural capital, would be that there are unmeasured inputs, such as the natural capital stock. The fact that the estimate of the user cost of natural capital is in most cases smaller than or equal to the difference between $\gamma^{\prime}$ and GDP in the OECD Productivity Database fits this idea nicely.

A simplified method is used to measure the user cost of produced capital for countries for which no data are available in the OECD Productivity Database. Namely, the cost share of produced capital is measured as the difference between nominal GDP and labour costs. Thus, MFP measurement relies on the 
assumptions of constant returns to scale and perfect competition in these cases, which implies zero residual profits. Hence, total costs are considered to equal GDP and the weights of inputs are measured as their income shares in GDP. Assigning all non-labour income to produced capital, obviously does not allow for unmeasured outputs and when they are present, their income would be included in the estimate of the cost (or income) of produced capital. In this case, total costs are not underestimated, but the share of produced capital in these costs is overestimated. Hence, in this case, only the cost share of capital needs to be adjusted downwards. The difference between the growth of produced and natural capital determines how productivity growth will have to be adjusted (Appendix 3).

$\frac{d \ln G M F P}{d t}=\frac{d \ln M F P}{d t}+\sum_{i} \frac{u_{S_{i}} S_{i}}{P_{Y} Y}\left(\frac{d \ln K}{d t}-\frac{d \ln S_{i}}{d t}\right)$

Equations (3) and (4) show in which ways standard measures of MFP growth can be biased when natural capital inputs are not considered. Essentially, when disregarding natural capital as an input factor, input growth is underestimated by the traditional MFP growth measure whenever the natural capital input, $\mathrm{S}$, grows faster than traditional inputs (in the case of exogenous measurement of the cost of capital) or produced capital (in the case of endogenous measurement of the cost of capital). As a result, productivity growth is overestimated, given that productivity growth is the difference between output and input growth. Conversely, if the use of natural capital in production grows more slowly than the combined growth of labour and capital inputs, aggregate input growth is overestimated and productivity growth is therefore underestimated. The adjustment is more pronounced, the larger the cost share of natural capital, as this will increase the weight of natural capital in the aggregate input index.

\section{The data}

The analysis is conducted with aggregate economy data for a sample of OECD and a few emerging countries. This study covers 23 OECD countries, Russia and South Africa (Table 1). Where data are available, the OECD Productivity Database is used to retrieve MFP growth and costs estimates, as well as input and output data. As mentioned above, the user cost of capital is estimated directly in this database ${ }^{2}$. National data sources are used for a range of countries, for which no data are available in the Productivity Database, i.e. for Chile, Mexico, Russia and South Africa ${ }^{3}$. Russian estimates are taken from Voskoboynikov (2012). The estimates for Chile, Mexico and South Africa are OECD calculations based on national data. The timeframe of the analysis is $1985-2008$ for some countries, shorter for countries where consistent data were not available over the whole period. Table 1 describes the dataset in more detail $^{4}$.

<place table 1 here>

\footnotetext{
${ }^{2}$ For a detailed description of the Productivity Database and methodology see OECD (2001) and the corresponding website (http://www.oecd.org/std/productivitystatistics).

${ }^{3}$ Cross-country comparability of some productivity estimates may be limited even countries do not employ similar methodologies in constructing measures of outputs and inputs. Such discrepancies could arise if GDP measures are constructed from the production side and without applying double deflation procedures to industry estimates of value-added. Applying single rather than double deflation methods can matter as a recent study by the U.K. Office of National Statistics (Franklin and Murphy 2014) has shown. They find that on average single deflation procedures under-estimate output (and productivity) growth although there are many differences between industries and between years. Another possible discrepancy may arise from differences in index number formulae: whereas OECD countries now all use chained index number formulae this is not always the case for non-OECD countries.
}

\footnotetext{
${ }^{4}$ The specific dataset underlying the present estimates is available with the online version of this paper.
} 
The coverage of natural capital in this analysis is constrained by data limitations. Even though the World Bank's wealth dataset is an important milestone for the creation of an international database on the production and use of natural capital, it is mainly focused on sub-soil assets. Specifically, the sub-soil assets covered in the dataset as well as in this analysis are oil, gas, bauxite, copper, lead, nickel, phosphate, tin, zinc, gold silver, iron ore, soft and hard coal. However, other types of natural capital which also contribute to the production process, such as water, soil, or renewable resources such as fish stocks, are not included in this analysis because data are not available.

Natural capital inputs are valued with their unit rent, which is the market price net of extraction costs. It can be shown that under the assumption of inter-temporarily optimal depletion of natural capital, the user cost of natural capital, i.e. the change in its value after depletion of one unit, equals its marginal resource rent, that is the market price net of marginal extraction cost (Appendix 2). In this paper these user costs are approximated with measures of unit rents provided by the World Bank. While marginal extraction costs would be the relevant measure for unit rents, these are not readily available. The World Bank therefore approximates marginal with average extraction costs and this approach is followed in this paper for lack of better data.

\section{Results}

The adjustment of the traditional productivity growth measure depends on natural capital input growth relative to other input factors. This can be seen in Table 2 and 3, where a noticeable adjustment to the traditional MFP growth measure can be observed for countries with significant natural capital endowments, such as Norway, Russia, Chile and Mexico and, to a lesser extent, the United Kingdom, Australia, Canada and the Netherlands. In Australia, Denmark, Norway, Finland and New Zealand the adjustment to the traditional MFP growth measure is negative, as natural capital grew faster on average over the sample period, than the traditional input index, combining labour and produced capital input growth only. In Australia, this was due to a strong generalised increase in minerals production, in Denmark and Norway to oil production and in New Zealand mainly to oil and gas production. By failing to account for a very fast-growing input factor, the traditional MFP growth measure overestimates productivity growth in these countries. Contrary to what one might be tempted to think, though, it is not necessarily the case that the traditional MFP growth measure overestimates productivity growth in countries with resource booms. In fact, Table 2 and $3^{5}$ show an upward adjustment of the productivity growth measure in Canada, Chile, Mexico, Russia and South Africa, all of which experienced a resource boom over the last years of the sample period. This is because during resource booms not only natural capital grows very fast, but other factor inputs do as well. In particular, there is often an investment boom associated with resource booms, originating in the resource sector, but often spilling over to other parts of the economy. So even if natural capital inputs grow very fast during resource booms, other inputs may grow even faster. In that case, the productivity growth measure is adjusted upwards, once natural capital is taken into account.

\section{<place table 2 here>}

The adjustment of the productivity growth measure is very likely positive, once natural capital endowments start to decline. Some countries, notably the United Kingdom, the United States and the Netherlands, experienced a decline in natural capital inputs over the sample period. This is because oil and gas reserves were dwindling already over the largest part of the period considered here. Productivity growth in these countries was stronger than the traditional MFP growth measure would suggest, because the failure to account for declining natural capital inputs leads to an overestimation of aggregate factor input growth, which is equivalent to an underestimation of productivity growth. Since labour and capital

\footnotetext{
${ }^{5}$ Note that productivity growth measures in Tables 2 and 3 are not comparable because of differences in the measurement of produced capital stock/capital services (see OECD, 2009, for details).
} 
generally tend to grow, save in very severe recessions, the adjustment will be negative when natural capital input growth is negative.

$$
\text { <place table } 3 \text { here> }
$$

The adjustment of the traditional MFP growth estimate may change over time, in particular when periods of resource scarcity follow resource abundance. This is the case for Norway (Figure 1). In the years up until 2000 when oil reserves were still relatively plentiful and the rate of extraction was fast, the use of natural capital grew faster than aggregate capital and labour inputs. As a result, the traditional MFP growth measure underestimates input growth in those years and productivity growth is overestimated. After 2000, however, as oil reserves in Norway became scarcer, the rate of oil extraction actually declined. Aggregate input growth is therefore overestimated if only labour and the capital stock are considered. As a result, the traditional MFP growth measure underestimates productivity growth.

\section{$<$ place figure 1 here >}

The size of the correction has sharply increased over the most recent years of the sample period in many countries, owing to a strong and generalised increase in commodity prices. This is the case regardless of whether productivity growth is corrected upwards or downwards. Given that the data series for Russia and South Africa starts only in 1995, and is thus shorter than for the rest of the countries, the strong weight of the correction term in the last years of the sample period also magnifies the average correction of productivity growth in these two countries compared to others. In fact, the correction is slightly negative on average between 1996 and 2004 in both Russia and South Africa, but much smaller than the positive correction after that (Figure 2). Another example is Norway (Figure 1). The sharp rise in oil and gas prices led to an increase in the share of natural capital rents in costs, thus magnifying the upward-correction of the traditional productivity growth estimate through the second term in equation (3). In New Zealand, the negative correction over the whole sample period is driven by strong spikes of oil and gas production in the last two years of the sample period, which are more strongly weighted than natural capital input developments in prior periods, owing to rising commodity prices (Figure 3). It is important to note that it is quite appropriate to give inputs a higher weight when their price increases. Producers would normally respond to an increase in the relative price of one input by substituting some of it with other now relatively cheaper inputs. Thus the relatively more expensive input should be expected to grow more slowly, the relatively cheaper inputs would grow faster. Assigning a higher weight to the input that now grows more slowly avoids mistaking this factor substitution as a general decrease in factor input growth, which would be equivalent to mistaking it for technological progress.

$$
\begin{aligned}
& \text { <place figure } 2 \text { here> } \\
& \text { <place figure } 3 \text { here > }
\end{aligned}
$$

Overall the growth contribution of natural capital is relatively small, compared to other production factors. Even in resource-rich countries, the share of natural capital income in overall production costs is hardly ever higher than 5\% (Table 2 and 3). As a consequence, the growth contribution of natural capital rarely attains a quarter of a percentage point. There are only a handful of countries where the growth contribution of natural capital is significant, including Australia, Chile, Norway, and Russia (Table 4). Yet, in all cases it is much smaller than the contribution of labour and produced capital. Small though it may be, it is still useful to have a clear picture of the growth contribution of natural capital. In this context, it is also important to note that subsoil assets capture a small part of countries' natural capital stock, leaving out many other aspects, such as land, water, natural forests and renewable resources, such as fish stock. Another aspect is that this paper looks at user costs of natural capital from the producer perspective. Finally, results in table 4 show the growth contribution of natural capital only from an accounting 
perspective. While that can give some interesting insights, the overall impact of resource booms and busts on economic growth is often larger through their effects on investment and the reaction of productivity growth.

\section{<place table 4 here>}

Growth accounting with natural capital is also useful to study the changing role of natural capital during times of abundance and scarcity. This can provide important information regarding the sustainability of growth. Figure 4 shows how the growth contribution of natural capital changed over time in Norway and the United Kingdom. From the mid-1980s to 2000 the growth contribution of natural capital was relatively large in Norway. After that it turned negative, as oil reserves started to diminish. Although the growth contribution of other factors of production increased a little, GDP growth declined almost in tandem with the growth contribution of natural capital. One interpretation would be that during times of resource abundance Norway did not invest sufficiently in other forms of wealth, such as human or physical capital, that would maintain its ability to generate GDP growth at the same high level, for example through higher productivity growth. It should be noted, however, that Norway has been investing a good part of its natural capital revenues in a foreign assets based sovereign wealth fund, thus transforming natural into financial capital for the benefit of future generations. The income generated from foreign assets does not contribute to GDP, but to national income (GNI). Yet, the average annual growth rate of GNI declined as much as the GDP growth rate over the two periods considered here, so taking the sovereign wealth fund into account does not change the picture described before. In the United Kingdom the growth contribution of natural capital was already very low during the first period. It then turned negative after 2000. However, MFP growth picked up to compensate for this negative growth contribution of natural capital, and GDP growth stayed roughly the same. Again, one interpretation would be that the United Kingdom invested sufficiently in human or knowledge capital to compensate the (small) drag on growth from a negative contribution from natural capital.

\section{<place figure 4 here>}

Growth accounting results suggest that the impact of resource booms on productivity and investment is important for an economy to benefit in terms of higher GDP growth. In Russia the resource boom that intensified towards the middle of the last decade was accompanied by an increase in both the produced capital stock growth and productivity growth (Figure 5). As a result, Russia benefitted through a substantial increase in GDP growth. In contrast, when comparing the same two episodes for Australia, it turns out that while the growth contribution of produced capital increased in the later period with a natural resource boom, productivity growth decelerated significantly. As a result, GDP growth actually declined. Likewise, New Zealand (Figure 6) did not benefit from higher GDP growth as a result of a higher growth contribution of natural capital and other factors of production over 2004-2008 compared to the earlier period, because productivity declined significantly at the same time, actually turning negative.

$$
\begin{aligned}
& \text { <place figure } 5 \text { here> } \\
& \text { <place figure } 6 \text { here > }
\end{aligned}
$$

Some countries are able to compensate declining contributions of natural capital through higher productivity growth, or produced capital. This was the case for Denmark (Figure 7) when comparing 20042008 with 1997-2003. Mexico, in contrast, experienced a decline in productivity growth along with the decline in the growth contribution of natural capital, but was able to compensate both with higher growth contribution of the produced capital stock.

<place figure 7 here > 


\section{Conclusions and further steps}

The main contribution of this paper is to develop a methodology to include natural capital into traditional measures of productivity growth, which can be developed further, as better and more extensive data on natural capital becomes available. In 2012, the international community agreed on a new accounting standard for environment-economic data (SEEA). Implementation of the SEEA will make available more physical and monetary data on natural capital, in particular land, aquatic resources and freshwater. Further insights might be gained by conducting this exercise at the industry level. The role of natural capital can obviously be attributed to the corresponding natural capital sectors, such as mining for energy and minerals. The growth contribution of natural capital in these sectors and their role for productivity growth will very likely be much greater than in the aggregate economy. An important future source of data for industry-level analysis will be data compiled in the framework of the System of Integrated Environmental Economy Accounts (SEEA) as it will be consistent with national accounts aggregates of inputs and outputs.

An important result is that the direction of the adjustment to productivity growth depends on the rate of change of natural capital extraction relative to the rate of change of other inputs. That implies - perhaps counterintuitively - that failing to account for natural capital may lead to an underestimation of productivity in resource booms, in case other factors of production, typically produced capital, grow even faster than natural resource inputs during such a boom.

Although the framework presented in this paper is not designed to track environmental sustainability as such, it provides useful insights into the role of natural capital for national income over. This will help researchers and policy makers better understand what happens when natural capital endowments become scarcer over time. 


\section{APPENDIX 1}

To include natural capital into productivity measurement the traditional production function is extended to include the flows of natural capital used in production, $S=\left[S_{1}, S_{2}, \ldots\right]$ which will in most cases correspond to natural resource extraction.

$Y=F(K, L, S, t)$

with $F_{K}, F_{L}, F_{S_{i}}>0, F_{K K}, F_{L L}, F_{S S_{i}}<0(\mathrm{i}=1,2, \ldots)$ as first- and second-order partial derivatives of the production function $F$. $Y$ denotes output, $L$, is labour input and $K$ is produced (as opposed to natural, nonproduced) capital and $t$ is an index of time.

Constant returns to scale in production are assumed, such that $\mathrm{F}$ is homogenous of degree one in $\mathrm{K}, \mathrm{L}$ and S. Totally differentiating (A1.1) with respect to time and rearranging yields

$\frac{d \ln G M F P}{d t} \equiv \frac{\partial \ln F}{\partial t}=\frac{d \ln Y}{d t}-\frac{F_{L} L}{Y} \frac{d \ln L}{d t}-\frac{F_{K} K}{Y} \frac{d \ln K}{d t}-\sum_{i} \frac{F_{S_{i}} S_{i}}{Y} \frac{d \ln S_{i}}{d t}$

where $F_{X}$ denotes the derivative of function $F(X,$.$) with respect to its argument X, \ln X$ denotes the natural logarithm of variable $X$ and its derivative with respect to time $t, \frac{d \ln X}{d t}$, corresponds to the growth rate of this variable. GMFP denotes Multi-Factor Productivity including natural capital.

If producers minimise costs, the marginal productivity of each input factor will equal its real input price. The cost minimisation problem reads:

$\operatorname{Min} \mathcal{L}=w L+u_{K} K+\sum_{i} u_{S_{i}} S_{i}+\lambda\left(\bar{Y}-F\left(L, K, S_{1}, S_{2}, S_{3}, \ldots, t\right)\right)$

with first order conditions for $L, K$, and $S: \frac{\partial \mathcal{L}}{\partial L}=w-\lambda F_{L}=0 ; \frac{\partial \mathcal{L}}{\partial K}=u_{K}-\lambda F_{K}=0 ; \frac{\partial \mathcal{L}}{\partial S_{i}}=u_{S_{i}}-$ $\lambda F_{S_{i}}=0$. Evaluating the Lagrange multiplier $\lambda$ and using the assumption of linear homogeneity of $\mathrm{F}$ yields:

$\gamma=w L+u_{K} K+\sum_{i} u_{S_{i}} S_{i}=\lambda\left(F_{L} L+F_{K} K+\sum_{i} F_{S_{i}} S_{i}\right)=\lambda F=\lambda Y \rightarrow \lambda=\frac{\gamma}{Y}$

where $\gamma$ corresponds to minimum costs. Given the valuation of $\lambda$ and the first order conditions, it follows that the production elasticities of inputs equal their income share in total costs:

$\frac{F_{L} L}{Y}=\frac{w L}{\lambda Y}=\frac{w L}{\gamma}$

$\frac{F_{K} K}{Y}=\frac{u_{K} K}{\lambda Y}=\frac{u_{K} K}{\gamma}$

$\frac{F_{S_{i}} S_{i}}{Y}=\frac{u_{S_{i}} S_{i}}{\lambda Y}=\frac{u_{S_{i}} S_{i}}{\gamma}$ 
Equation (A1.2) can thus be written as

$\frac{d \ln G M F P}{d t}=\frac{d \ln Y}{d t}-\frac{w L}{\gamma} \frac{d \ln L}{d t}-\frac{u_{K} K}{\gamma} \frac{d \ln K}{d t}-\sum_{i} \frac{u_{S_{i}} S_{i}}{\gamma} \frac{d \ln S_{i}}{d t}$

Denoting total factor input costs in the traditional MFP framework by $\gamma^{\prime} \equiv w L+u_{K} K$, it can be shown that the ratio between the traditional and the extended input cost measure is $\frac{\gamma^{\prime}}{\gamma}=1-\sum_{i} \frac{u_{S_{i}} S_{i}}{\gamma}$. A shorthand measure $Z=Z(L, K)$ is used for the volume aggregate of traditional labour and capital inputs whose growth rate is given by

$\frac{d \ln Z}{d t} \equiv\left(\frac{w L}{\gamma^{\prime}} \frac{d \ln L}{d t}+\frac{u_{K} K}{\gamma^{\prime}} \frac{d \ln K}{d t}\right)$

such that

$\frac{d \ln M F P}{d t}=\frac{d \ln Y}{d t}-\frac{d \ln Z}{d t}$

Equation (A1.8) can then be rewritten as:

$\frac{d \ln G M F P}{d t}=\frac{d \ln Y}{d t}-\frac{\gamma^{\prime}}{\gamma}\left(\frac{w L}{\gamma^{\prime}} \frac{d \ln L}{d t}+\frac{u_{K} K}{\gamma^{\prime}} \frac{d \ln K}{d t}\right)-\sum_{i} \frac{u_{S_{i}} S_{i}}{\gamma} \frac{d \ln S_{i}}{d t}$

$\frac{d \ln G M F P}{d t}=\frac{d \ln M F P}{d t}+\left(1-\frac{\gamma^{\prime}}{\gamma}\right) \frac{d \ln Z}{d t}-\sum_{i} \frac{u_{S_{i}} S_{i}}{\gamma} \frac{d \ln S_{i}}{d t}$

$\frac{d \ln G M F P}{d t}=\frac{d \ln M F P}{d t}+\sum_{i} \frac{u_{S_{i}} S_{i}}{\gamma}\left(\frac{d \ln Z}{d t}-\frac{d \ln S_{i}}{d t}\right)$

This equation shows that the difference between the traditional MFP growth measure and the extended measure, including natural capital, will depend on the difference between the growth rate of the traditional composite input index, comprising labour and produced capital only, and the growth in the use of natural capital S, as well as on the share of natural capital rents in production.

Note that in practice, traditional productivity growth and the adjusted productivity growth are measured as a discrete time version of (A1.8) and (A1.10) respectively. We employ a version of Morrison and Diewert (1990) and use first-order approximations to our continuous form expressions to demonstrate that Törnqvist indices constitute an appropriate form for measurement in practice.

We start by approximating the continuous logarithmic rate of productivity change $\frac{\operatorname{dlnGMFP}}{d t} \equiv$ $\frac{\partial \ln F\left(L, K, S_{1}, S_{2}, S_{3}, \ldots t\right)}{\partial t}$ in two alternative ways: (i) as a shift of the production function predicated over inputs in 
period $\mathrm{t}$ - a Paasche-type productivity measure - and (ii) as a shift of the production function predicated over inputs in period t-1 - a Laspeyres-type productivity measure. Call these $\triangle \ln G M F P_{P}{ }^{t}$ and $\triangle \ln G M F P_{L}{ }^{t}$ respectively with the following definitions:

$$
\begin{aligned}
& \Delta \ln G M F P_{P}^{t} \equiv \ln F^{t}\left(L^{t}, K^{t}, S_{1}^{t}, S_{2}^{t}, S_{3}^{t}, \ldots\right)-\ln F^{t-1}\left(L^{t}, K^{t}, S_{1}^{t}, S_{2}^{t}, S_{3}^{t}, \ldots\right) \\
& \Delta \ln G M F P_{L}^{t} \equiv \ln F^{t}\left(L^{t-1}, K^{t-1}, S_{1}^{t-1}, S_{2}^{t-1}, S_{3}^{t-1}, \ldots\right)-\ln F^{t-1}\left(L^{t-1}, K^{t-1}, S_{1}^{t-1}, S_{2}^{t-1}, S_{3}^{t-1}, \ldots\right)
\end{aligned}
$$

Next, approximate each of these expressions with a first-order Taylor series. In the Paasche case, this yields:

$$
\begin{aligned}
\Delta \ln G M F P_{P}^{t} \equiv & \ln F^{t}\left(L^{t}, K^{t}, S_{1}^{t}, S_{2}^{t}, S_{3}^{t}, \ldots\right)-\ln F^{t-1}\left(L^{t}, K^{t}, S_{1}^{t}, S_{2}^{t}, S_{3}^{t}, \ldots\right) \\
& \approx \ln F^{t}\left(L^{t}, K^{t}, S_{1}^{t}, S_{2}^{t}, S_{3}^{t}, \ldots\right) \\
& -\left[\ln F^{t-1}\left(L^{t-1}, K^{t-1}, S_{1}^{t-1}, S_{2}^{t-1}, S_{3}^{t-1}, \ldots\right)+\frac{\partial \ln F^{t-1}}{\partial \ln L^{t-1}}\left(\ln L^{t}-\ln L^{t-1}\right)\right. \\
& \left.+\frac{\partial \ln F^{t-1}}{\partial \ln K^{t-1}}\left(\ln K^{t}-\ln K^{t-1}\right)+\sum_{i} \frac{\partial \ln F^{t-1}}{\partial \ln S_{i}^{t-1}}\left(\ln S_{i}^{t}-\ln S_{i}^{t-1}\right)\right] \\
& =\Delta \ln Y^{t}-\left[\frac{w^{t-1} L^{t-1}}{\gamma^{t-1}} \Delta \ln L^{t}+\frac{u_{K}^{t-1} K^{t-1}}{\gamma^{t-1}} \Delta \ln K^{t}+\sum_{i} \frac{u_{S_{i}}^{t-1} S_{i}^{t-1}}{\gamma^{t-1}} \Delta \ln S_{i}^{t}\right]
\end{aligned}
$$

where $\Delta X^{t} \equiv X^{t}-X^{t-1}$ is a difference operator. The expression in the last row follows from the production relation $Y^{t}=F^{t}\left(L^{t}, K^{t}, S_{1}^{t}, S_{2}^{t}, S_{3}^{t}, \ldots\right)$ and the first-order conditions for a producer maximum. Similarly, the Laspeyres case gives rise to the following expression:

$$
\begin{aligned}
\Delta \ln G M F P_{L}^{t} \equiv & \ln F^{t}\left(L^{t-1}, K^{t-1}, S_{1}^{t-1}, S_{2}^{t-1}, S_{3}^{t-1}, \ldots\right) \\
& -\ln F^{t-1}\left(L^{t-1}, K^{t-1}, S_{1}^{t-1}, S_{2}^{t-1}, S_{3}^{t-1}, \ldots\right) \\
& \approx-\ln F^{t-1}\left(L^{t-1}, K^{t-1}, S_{1}^{t-1}, S_{2}^{t-1}, S_{3}^{t-1}, \ldots\right) \\
& +\left[\ln F^{t}\left(L^{t}, K^{t}, S_{1}^{t}, S_{2}^{t}, S_{3}^{t}, \ldots\right)-\frac{\partial \ln F^{t}}{\partial \ln L^{t}}\left(\ln L^{t}-\ln L^{t-1}\right)\right. \\
& \left.-\frac{\partial \ln F^{t}}{\partial \ln K^{t}}\left(\ln K^{t}-\ln K^{t-1}\right)-\sum_{i} \frac{\partial \ln F^{t}}{\partial \ln S_{i}^{t}}\left(\ln S_{i}^{t}-\ln S_{i}^{t-1}\right)\right] \\
& =\Delta \ln Y^{t}-\left[\frac{w^{t} L^{t}}{\gamma^{t}} \Delta \ln L^{t}+\frac{u_{K}^{t} K^{t}}{\gamma^{t}} \Delta \ln K^{t}+\sum_{i} \frac{u_{S_{i}}^{t} S_{i}^{t}}{\gamma^{t}} \Delta \ln S_{i}^{t}\right]
\end{aligned}
$$

As there is no particular reason to prefer the Paasche approximation over the Laspeyres approximation, we form an arithmetic average $\Delta \ln G M F P^{t} \equiv 0.5\left(\Delta \ln G M F P_{P}{ }^{t}+\Delta \ln G M F P_{L}{ }^{t}\right)$ and so obtain a Törnqvist index of productivity change. Re-arranged, we have an expression for the rate of adjusted productivity change between $t$ and $t-1$ : 


$$
\begin{aligned}
& \Delta \ln G M F P^{t} \equiv 0.5\left(\Delta \ln G M F P_{P}^{t}+\Delta \ln G M F P_{L}^{t}\right) \\
&=\Delta \ln Y^{t}-\left[0.5\left(\frac{w^{t} L^{t}}{\gamma^{t}}+\frac{w^{t-1} L^{t-1}}{\gamma^{t-1}}\right) \Delta \ln L^{t}+0.5\left(\frac{u_{K}^{t} K^{t}}{\gamma^{t}}+\frac{u_{K}^{t-1} K^{t-1}}{\gamma^{t-1}}\right) \Delta \ln K^{t}\right. \\
&\left.+\sum_{i} \mathbf{0 . 5}\left(\frac{\boldsymbol{u}_{S_{i}}^{t} S_{i}^{t}}{\gamma^{t}}+\frac{\boldsymbol{u}_{S_{i}}^{t-1} S_{i}^{t-1}}{\gamma^{t-1}}\right) \Delta \ln S_{i}^{t}\right]
\end{aligned}
$$

Equation A1.15 forms the basis for the empirical approximation of the continuous-time Divisia index formula for productivity growth. A similar reasoning applies to the discrete approximation to traditional MFP growth.

\section{APPENDIX 2}

The optimal extraction of a non-renewable capital stock $N(t)$ over a lifetime $T$, which is depleted at the quantity $S(t)$ in period $t$ follows:

$\left.\max _{\mathrm{S}(\mathrm{a})} V(t)=\int_{t}^{T-t} R_{S}(a, S(a)), N(a)\right) e^{-r(a-t)} d a$

given $\dot{N}=-S(t)$.

$\mathrm{V}(\mathrm{t})$ is thus the net present value of resource rents, $\mathrm{R}_{\mathrm{S}}(\mathrm{t}, \mathrm{S}(\mathrm{t}))$, which corresponds to the revenues from natural capital extraction net of costs $R_{S}=P_{S}(t) S(t)-C_{S}(S(t), t)$, where total costs, $C_{S}$, include a normal return. $\mathrm{P}_{\mathrm{S}}$ is the market price at which the extracted natural capital can be sold and $\mathrm{r}$ is a nominal interest rate. To keep things simple, it is assumed that resource rents do not depend on the remaining stock of natural capital, N. The present value Hamiltonian for this optimization problem is:

$H(S(t), \lambda(t))=R_{S}(t, S(t))-\lambda(t) S(t)$

The static efficiency condition then requires:

$\frac{\partial H}{\partial S}=\frac{\partial R_{S}}{\partial S}-\lambda(t)=0$

Because $\lambda(t)$ is the shadow cost of using (depleting) one unit of the capital stock, in terms of the associated change of the present value of resource rents, it can be interpreted as the user cost of the natural capital, $\mathrm{u}_{\mathrm{S}}$. In the case of unit extraction costs that are independent of the level of extraction $\frac{\partial C_{S}}{\partial S}=\bar{c}_{S}(t)$, resource rents can be expressed as $R_{S}(t, S(t))=P_{S}(t) S(t)-C_{S}(S(t), t)=P_{S}(t) S(t)-\bar{c}_{S}(t) S(t)$, in which case equation (A2.3) states that the user cost of the natural capital equals its unit rent $\frac{\partial R_{S}}{\partial S}=\frac{R_{S}}{S}=$ $P_{S}(t)-\bar{c}_{S}(t)=u_{S}(t)$. In that case, user costs can be measured as the surplus market price of the natural capital, $P_{S}$, over extraction costs. This is the World Bank method applied in this paper. 


\section{APPENDIX 3}

For some countries, where data necessary to estimate the user costs of capital directly is difficult to find, MFP growth estimates are based on the assumption that all non-labour income accrues to capital and hence the user cost of capital is calculated as a residual. In this case, the natural capital rents are picked up by the cost share allocated to produced capital K. As a consequence, the cost share of capital is overstated if indeed some of this income accrues to natural capital instead. This implies that the user cost as measured in this framework is actually composed of two parts, the true user cost of produced capital and the user cost of natural capital: $u_{K}^{\prime} K=u_{K} K+\sum_{i} u_{S_{i}} S_{i}=P_{Y} Y-w L$. Total input costs are equal to value added, because this measurement framework relies on the assumptions of constant returns to scale and perfect competition, which implies zero profits. In that case equation (1) from the main text can be written as

$\frac{d \ln M F P}{d t}=\frac{d \ln Y}{d t}-\left(\frac{w L}{P_{Y} Y} \frac{d \ln L}{d t}+\frac{u_{K}^{\prime} K}{P_{Y} Y} \frac{d \ln K}{d t}\right)$

Using $u_{K}^{\prime} K=u_{K} K+u_{S} S$, equation (A3.1) can be rewritten as

$\frac{d \ln M F P}{d t}=\frac{d \ln Y}{d t}-\left(\frac{w L}{P_{Y} Y} \frac{d \ln L}{d t}+\frac{u_{K} K}{P_{Y} Y} \frac{d \ln K}{d t}+\sum_{i} \frac{u_{S i} S_{i}}{P_{Y} Y} \frac{d \ln K}{d t}\right)$

For the adjusted productivity measure, refer again to a cost minimisation as in (A.1.4). Imposing full competition implies zero profits, so $\gamma=\mathrm{P}_{\mathrm{Y}} \mathrm{Y}$, and equation (A1.4) can be written as

$P_{Y} Y=w L+u_{K} K+\sum_{i} u_{S_{i}} S_{i}=\lambda\left(F_{L} L+F_{K} K+\sum_{i} F_{S_{i}} S_{i}\right)=\lambda F=\lambda Y \rightarrow \lambda=\frac{P_{Y} Y}{Y}$

The elasticities of the inputs can be rewritten as $\frac{F_{L} L}{Y}=\frac{w L}{P_{Y} Y}, \frac{F_{K} K}{Y}=\frac{u_{K} K}{P_{Y} Y}, \frac{F_{S_{i}} S_{i}}{Y}=\frac{u_{S_{i}} S_{i}}{P_{Y} Y}$. The equation for the adjusted MFP measure is then given by:

$\frac{d \ln G M F P}{d t}=\frac{d \ln Y}{d t}-\frac{w L}{P_{Y} Y} \frac{d \ln L}{d t}-\frac{u_{K} K}{P_{Y} Y} \frac{d \ln K}{d t}-\sum_{i} \frac{u_{S_{i}} S_{i}}{P_{Y} Y} \frac{d \ln S_{i}}{d t}$

which is equivalent to equation (A1.8) remembering that nominal GDP equals total costs in the framework described in this appendix, $P_{Y} Y=\gamma$. Comparing (A3.4) with equation (A3.2) yields:

$\frac{d \ln G M F P}{d t}=\frac{d \ln M F P}{d t}+\sum_{i} \frac{u_{S i} S_{i}}{P_{Y} Y}\left(\frac{d \ln K}{d t}-\frac{d \ln S_{i}}{d t}\right)$

This shows that in this framework, the difference between the traditional MFP growth measure and the measure including the natural capital stock, depends on the difference between the growth rate of natural capital and produced capital services and the share of natural capital rents in GDP, a somewhat different expression from (A.1.11). This equation is used to calculate the adjusted MFP growth measure for countries where the user cost of capital is calculated as a residual, i.e. Chile, South Africa, Mexico and Russia.

Again equations (A3.4) and (A3.1) are in practice measured as Törnqvist indexes. GMFP growth is thus given by 


$$
\begin{aligned}
\Delta \ln G M F P^{t}= & \Delta \ln Y^{t}-0.5\left(\frac{w^{t} L^{t}}{P_{Y}^{t} Y^{t}}+\frac{w^{t-1} L^{t-1}}{P_{Y}^{t-1} Y^{t-1}}\right) \Delta \ln L^{t}-0.5\left(\frac{u_{K}^{t} K^{t}}{P_{Y}^{t} Y^{t}}+\frac{u_{K}^{t-1} K^{t-1}}{P_{Y}^{t-1} Y^{t-1}}\right) \Delta \ln K^{t} \\
& -\sum_{i} 0.5\left(\frac{u_{S_{i}}^{t} S_{i}^{t}}{P_{Y}^{t} Y^{t}}+\frac{u_{S_{i}}^{t-1} S_{i}^{t-1}}{P_{Y}^{t-1} Y^{t-1}}\right) \Delta \ln S_{i}^{t}
\end{aligned}
$$

Traditional MFP growth is measured as

$$
\Delta \ln M F P^{t}=\Delta \ln Y^{t}-0.5\left(\frac{w^{t} L^{t}}{P_{Y}^{t} Y^{t}}+\frac{w^{t-1} L^{t-1}}{P_{Y}^{t-1} Y^{t-1}}\right) \Delta \ln L^{t}-0.5\left(\frac{u_{K}^{t} K^{t}}{P_{Y}^{t} Y^{t}}+\frac{u_{K}^{t-1} K^{t-1}}{P_{Y}^{t-1} Y^{t-1}}\right) \Delta \ln K^{t}
$$

\section{BIBLIOGRAPHY}

Cho, T., J. Kim and P. Schreyer, "Measuring the Evolution of Korea's Material Living Standards 19802010"; Journal of Productivity Analysis, 2014 (forthcoming).

Diewert, W. E. and A. Nakamura, "The Measurement of Aggregate Total Factor Productivity Growth", in J. J. Heckman and E. E. Leamer, eds., Handbook of Econometrics, 4502-4530, Elsevier Science Publishing, Amsterdam, 2007.

Franklin, M. and J. Murphy, "Labour Productivity Measures from the ABS 2008-2012"; Office of National Statistics, London, 2014; available under http://www.ons.gov.uk/ons/dcp171766_354590.pdf.

Jorgenson, D. W., Productivity, Volumes 1 and 2, MIT Press, Cambridge Mass. and London, 1995.

Morrison, C.J. and W.E. Diewert (1990), "Productivity Growth and Changes in the Terms of Trade in Japan and the United States", in Productivity Growth in Japan and the United States, 201-227, University of Chicago Press, Chicago, 1990.

OECD, Measuring Productivity, OECD Publishing, Paris, 2001. , Measuring Capital: OECD Manual, OECD Publishing, Paris, 2009.

Voskoboynikov, I. B., "New Measures of Output, Labour and Capital in Industries of the Russian Economy", Research Memorandum of Groningen Growth and Development Centre GD-123, 2012.

World Bank, The Changing Wealth of Nations: Measuring Sustainable Development in the New Millennium, Washington, USA, 2011. 


\section{TABLES}

Table 1. Dataset summary table

\begin{tabular}{|c|c|c|c|}
\hline Variable & Source & Countries covered & $\begin{array}{l}\text { Time period } \\
\text { covered }\end{array}$ \\
\hline $\begin{array}{l}\text { MFP, GDP, labour, } \\
\text { produced capital, } \\
\text { wage share and user } \\
\text { costs of capital }\end{array}$ & $\begin{array}{l}\text { OECD } \\
\text { Productivity } \\
\text { database }\end{array}$ & $\begin{array}{l}\text { AUS, AUT, BEL, CAN, CHE, DEU, DNK, ESP, FIN, FRA, } \\
\text { GBR, IRL, ITA, JPN, KOR, NLD, NOR, NZL, PRT, SWE, } \\
\text { USA }\end{array}$ & $1985-2008$ \\
\hline $\begin{array}{l}\text { MFP, GDP, labour, } \\
\text { produced capital, } \\
\text { wage share }\end{array}$ & $\begin{array}{l}\text { National } \\
\text { Source }\end{array}$ & $\mathrm{CHL}^{1)}, \mathrm{MEX}^{2)}, \mathrm{RUS}^{3)}, \mathrm{ZAF}$ & $1996-2008$ \\
\hline Natural capital data & World Bank & $\begin{array}{l}\text { AUS, AUT, BEL, CAN, CHE, CHL, DEU, DNK, ESP, FIN, } \\
\text { FRA, GBR, IRL, ITA, JPN, KOR, MEX, NLD, NOR, NZL, } \\
\text { PRT, SWE, USA, RUS, ZAF }\end{array}$ & $1985-2008$ \\
\hline Natural capital rent & World Bank & $\begin{array}{l}\text { AUS, AUT, BEL, CAN, CHE, CHL, DEU, DNK, ESP, FIN, } \\
\text { FRA, GBR, IRL, ITA, JPN, KOR, MEX, NLD, NOR, NZL, } \\
\text { PRT, SWE, USA, RUS, ZAF }\end{array}$ & $1985-2008$ \\
\hline
\end{tabular}

1) Productivity data for Chile covers 1997 - 2008.

2) Productivity data (1996 - 2008) are calculated on the basis of a dataset kindly provided by the Instituto Nacional de Estadistica y Geografia from Mexico

3) Productivity data for Russia (1996 - 2008) were generously provided by llya B. Voskoboynikov. For more details on the dataset see the corresponding paper (Voskoboynikov, 2012).

Table 2. Average productivity growth per year, with and without natural capital

Based on data from the OECD Productivity Database, 1986-2008 ${ }^{1}$

\begin{tabular}{|c|c|c|c|c|c|c|}
\hline Country & $\begin{array}{l}\text { Traditional MFP } \\
\text { growth in } \%\end{array}$ & $\begin{array}{l}\text { MFP growth } \\
\text { with natural } \\
\text { resources in \% }\end{array}$ & $\begin{array}{l}\text { Difference in } \\
\text { percentage } \\
\text { points }\end{array}$ & $\begin{array}{l}\text { Traditional } \\
\text { inputs growth } \\
\text { in } \%\end{array}$ & $\begin{array}{l}\text { Natural capital } \\
\text { growth in } \%\end{array}$ & $\begin{array}{l}\text { Share of } \\
\text { resource rent in } \\
\text { total cost in \% }\end{array}$ \\
\hline 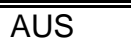 & 0.92 & 0.88 & -0.04 & 2.41 & "4.14 & $\bar{~} 4.35$ \\
\hline AUT & 1.43 & 1.44 & 0.00 & 1.14 & 0.19 & 0.21 \\
\hline BEL & 1.32 & 1.32 & 0.00 & 0.99 & -20.00 & 0.00 \\
\hline CAN & 0.38 & 0.42 & 0.04 & 2.26 & 1.51 & 3.97 \\
\hline $\mathrm{CHE}$ & 0.06 & 0.06 & 0.00 & 1.42 & -6.96 & 0.00 \\
\hline DEU & 1.10 & 1.11 & 0.01 & 0.38 & -1.00 & 0.19 \\
\hline DNK & 0.75 & 0.72 & -0.03 & 1.27 & 7.91 & 2.25 \\
\hline ESP & 0.35 & 0.35 & 0.01 & 2.87 & -10.52 & 0.06 \\
\hline FIN & 2.07 & 2.07 & -0.01 & 0.54 & 6.88 & 0.07 \\
\hline FRA & 1.06 & 1.06 & 0.00 & 1.03 & -6.15 & 0.05 \\
\hline GBR & 1.26 & 1.33 & 0.08 & 1.43 & -1.20 & 2.09 \\
\hline IRL & 2.84 & 2.86 & 0.02 & 2.40 & -7.05 & 0.34 \\
\hline ITA & 0.45 & 0.45 & 0.00 & 1.20 & 0.19 & 0.21 \\
\hline JPN & 1.46 & 1.46 & 0.00 & 0.53 & 0.63 & 0.02 \\
\hline KOR & 3.93 & 3.93 & 0.00 & 2.47 & -6.54 & 0.05 \\
\hline NLD & 0.95 & 1.00 & 0.05 & 1.85 & -0.69 & 1.83 \\
\hline NOR & 1.18 & 1.02 & -0.16 & 1.46 & 4.97 & 16.77 \\
\hline NZL & 0.68 & 0.66 & -0.02 & 1.78 & 2.11 & 1.41 \\
\hline PRT & 1.29 & 1.29 & 0.00 & 1.17 & -3.31 & 0.01 \\
\hline SWE & 1.03 & 1.03 & 0.00 & 1.26 & 0.08 & 0.23 \\
\hline
\end{tabular}


1996-2007 for Austria, 1986-2004 for Belgium, 1991-2008 for Switzerland, 1992-2008 for Germany, 1986-2007 for the Netherlands, Denmark, United Kingdom, and 1996-2005 for Portugal

Table 3. Average productivity growth per year, with and without natural capital

Based on national data, $1996-2008^{1}$

\begin{tabular}{lrllrrr}
\hline Country & $\begin{array}{l}\text { Traditional MFP } \\
\text { growth in \% }\end{array}$ & $\begin{array}{l}\text { MFP growth } \\
\text { with natural } \\
\text { resources in \% }\end{array}$ & $\begin{array}{l}\text { Difference in } \\
\text { percentage } \\
\text { points }\end{array}$ & $\begin{array}{l}\text { Capital stock } \\
\text { growth in \% }\end{array}$ & $\begin{array}{l}\text { Natural capital } \\
\text { growth in\% }\end{array}$ & $\begin{array}{l}\text { Share of } \\
\text { resource rent in } \\
\text { GDP in \% }\end{array}$ \\
\hline \hline CHL & 0.90 & 1.10 & 0.21 & 5.07 & 4.18 & 6.63 \\
MEX & 0.97 & 1.09 & 0.12 & 2.81 & 0.84 & 3.73 \\
RUS & 2.21 & 2.50 & 0.28 & 3.16 & 2.12 & 13.32 \\
ZAF & 1.62 & 1.70 & 0.07 & 2.01 & 0.65 & 2.35 \\
\hline \hline
\end{tabular}

1997-2008 for Chile

Table 4. Growth accounting results incorporating the natural capital stock

\begin{tabular}{|c|c|c|c|c|c|}
\hline Country & $\begin{array}{l}\text { MFP growth } \\
\text { adjusted } \\
\text { (natural } \\
\text { resources) in \% }\end{array}$ & $\begin{array}{l}\text { GDP } \\
\text { growth in } \\
\%\end{array}$ & $\begin{array}{l}\text { Growth } \\
\text { contribution } \\
\text { of labour } \\
\text { input in \% }\end{array}$ & $\begin{array}{l}\text { Growth } \\
\text { contribution } \\
\text { of capital } \\
\text { input in \% }\end{array}$ & $\begin{array}{l}\text { Growth } \\
\text { contribution } \\
\text { of natural } \\
\text { capital in \% }\end{array}$ \\
\hline AUS & 0.88 & 3.34 & 1.26 & 1.05 & 0.15 \\
\hline AUT & 1.44 & 2.60 & 0.57 & 0.57 & 0.00 \\
\hline BEL & 1.32 & 2.28 & 0.24 & 0.75 & 0.00 \\
\hline CAN & 0.42 & 2.67 & 1.11 & 1.06 & 0.05 \\
\hline $\mathrm{CHE}$ & 0.06 & 1.46 & 0.60 & 0.82 & 0.00 \\
\hline $\mathrm{CHL}$ & 1.10 & 4.09 & 0.81 & 2.04 & 0.14 \\
\hline DEU & 1.11 & 1.48 & -0.21 & 0.58 & 0.00 \\
\hline DNK & 0.72 & 2.00 & 0.24 & 0.99 & 0.06 \\
\hline ESP & 0.35 & 3.22 & 1.63 & 1.24 & 0.00 \\
\hline FIN & 2.07 & 2.63 & -0.04 & 0.58 & 0.01 \\
\hline FRA & 1.06 & 2.08 & 0.31 & 0.71 & 0.00 \\
\hline GBR & 1.33 & 2.68 & 0.46 & 0.94 & -0.04 \\
\hline $\mathrm{IRL}$ & 2.86 & 5.25 & 1.52 & 0.87 & -0.01 \\
\hline ITA & 0.45 & 1.64 & 0.39 & 0.81 & 0.00 \\
\hline JPN & 1.46 & 1.99 & -0.36 & 0.88 & 0.00 \\
\hline KOR & 3.93 & 6.39 & 0.72 & 1.74 & 0.00 \\
\hline MEX & 1.09 & 3.49 & 0.86 & 1.54 & -0.01 \\
\hline NLD & 1.00 & 2.78 & 0.99 & 0.83 & -0.01 \\
\hline NOR & 1.02 & 2.64 & 0.36 & 0.80 & 0.46 \\
\hline NZL & 0.66 & 2.45 & 0.85 & 0.90 & 0.04 \\
\hline PRT & 1.29 & 2.47 & 0.31 & 0.86 & 0.00 \\
\hline RUS & 2.50 & 4.53 & 0.66 & 0.86 & 0.27 \\
\hline SWE & 1.03 & 2.33 & 0.30 & 0.95 & 0.00 \\
\hline USA & 1.05 & 2.84 & 0.94 & 0.89 & -0.01 \\
\hline ZAF & 1.70 & 3.61 & 1.00 & 0.93 & -0.01 \\
\hline
\end{tabular}

${ }^{1}$ 1996-2007 for Austria, Mexico, Russia, South Africa, 1986-2004 for Belgium, 1991-2008 for Switzerland, 1992-2008 for Germany, 1986-2007 for the Netherlands, Denmark, United Kingdom, 1996-2005 for Portugal, 1997-2008 for Chile 


\section{FIGURES}

Figure 1. Difference between MFP growth adjusted for natural capital inputs and traditional MFP growth Norway

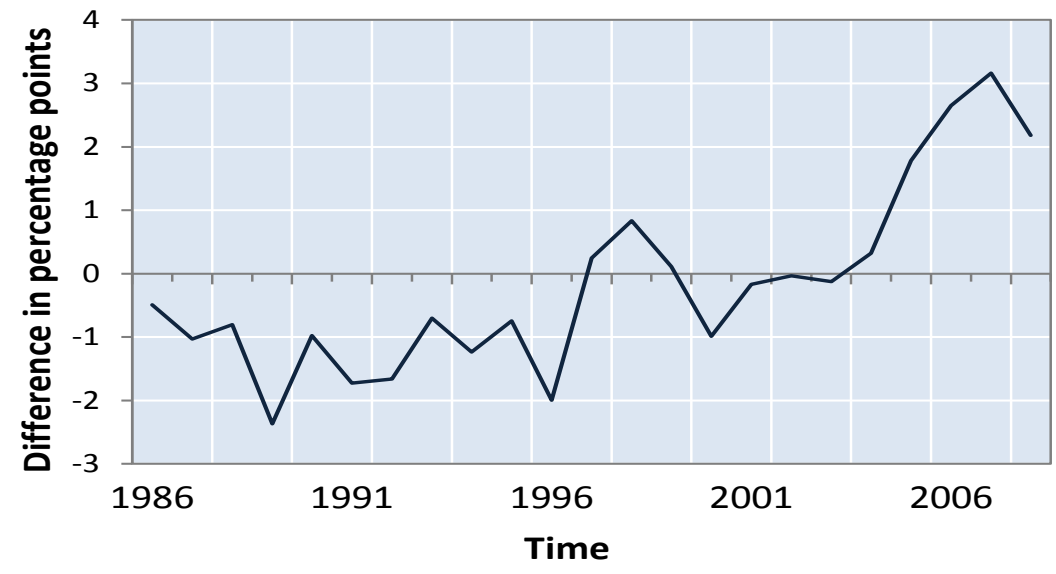

Figure 2. Difference between MFP growth adjusted for natural capital inputs and traditional MFP growth
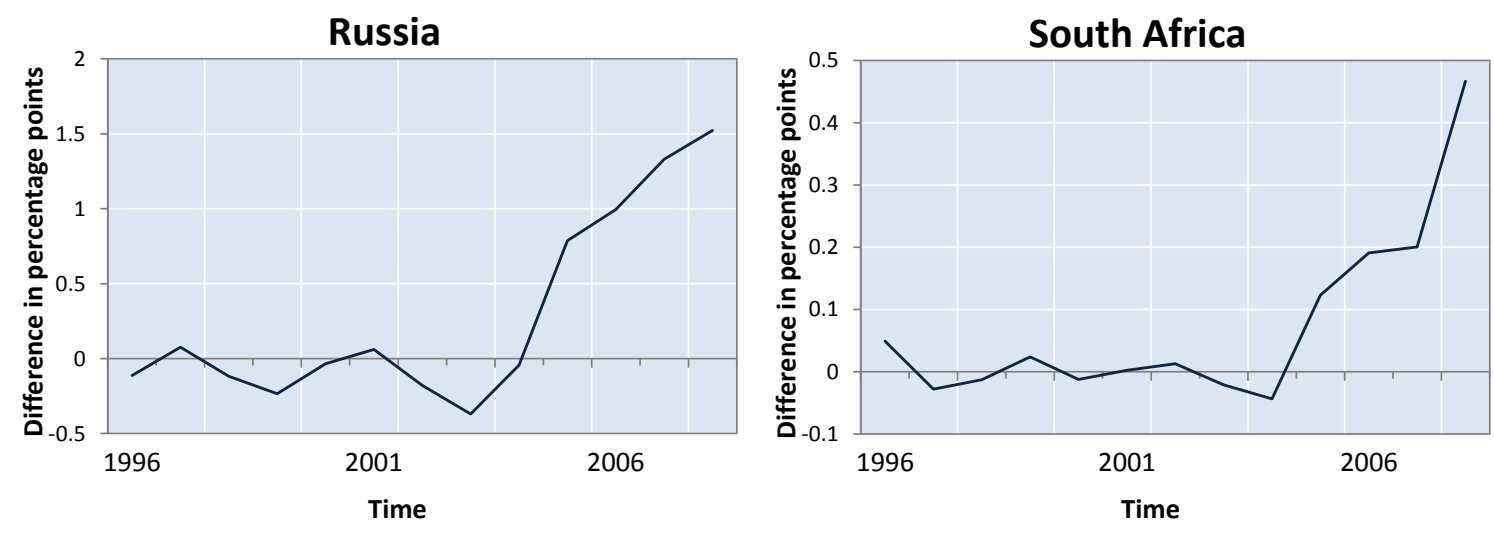
Figure 3. Difference between MFP growth adjusted for natural capital inputs and traditional MFP growth New Zealand

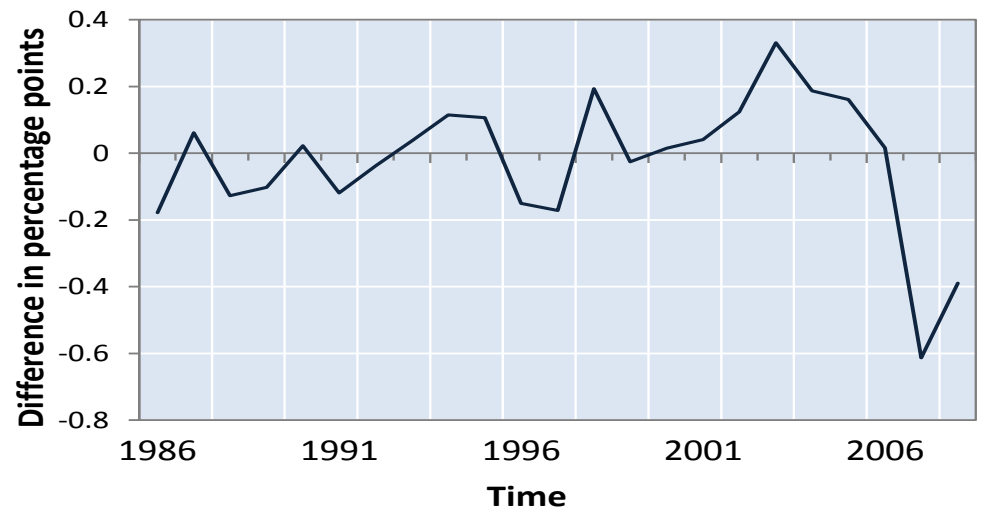

Figure 4. GDP growth and contributions - Norway and United Kingdom
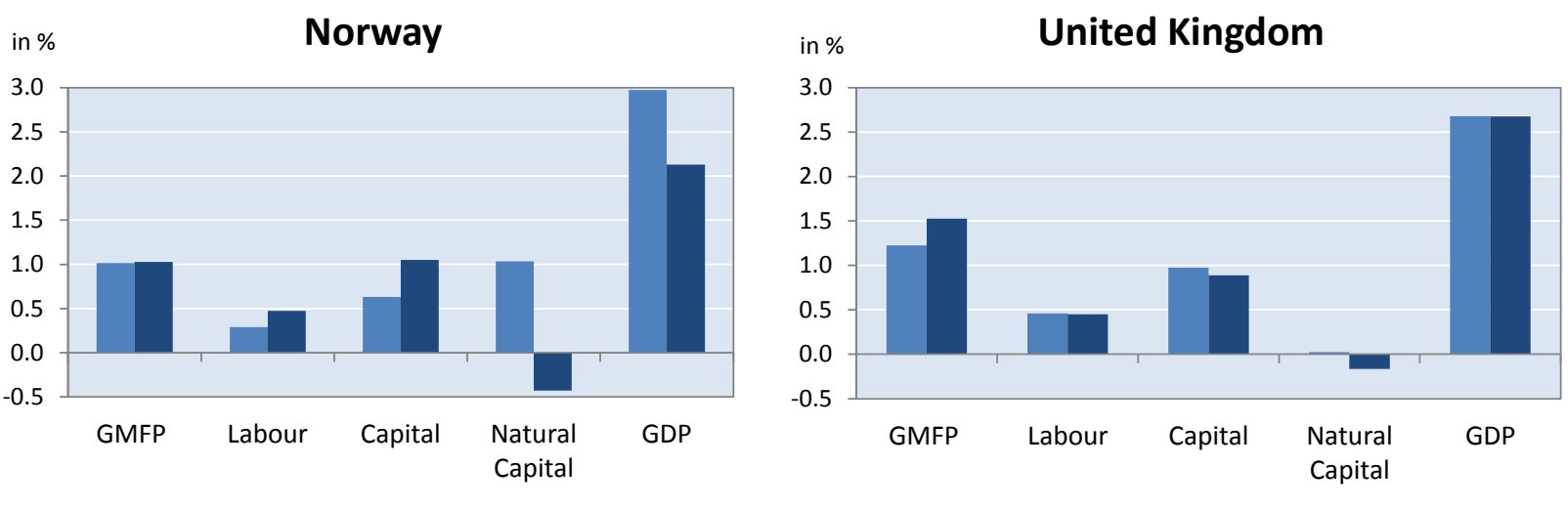

ロ $1986-1999 \square 2000-2008$

- $1986-1999 \square 2000-2008$ 
Figure 5. GDP growth and contributions - Australia and Russia
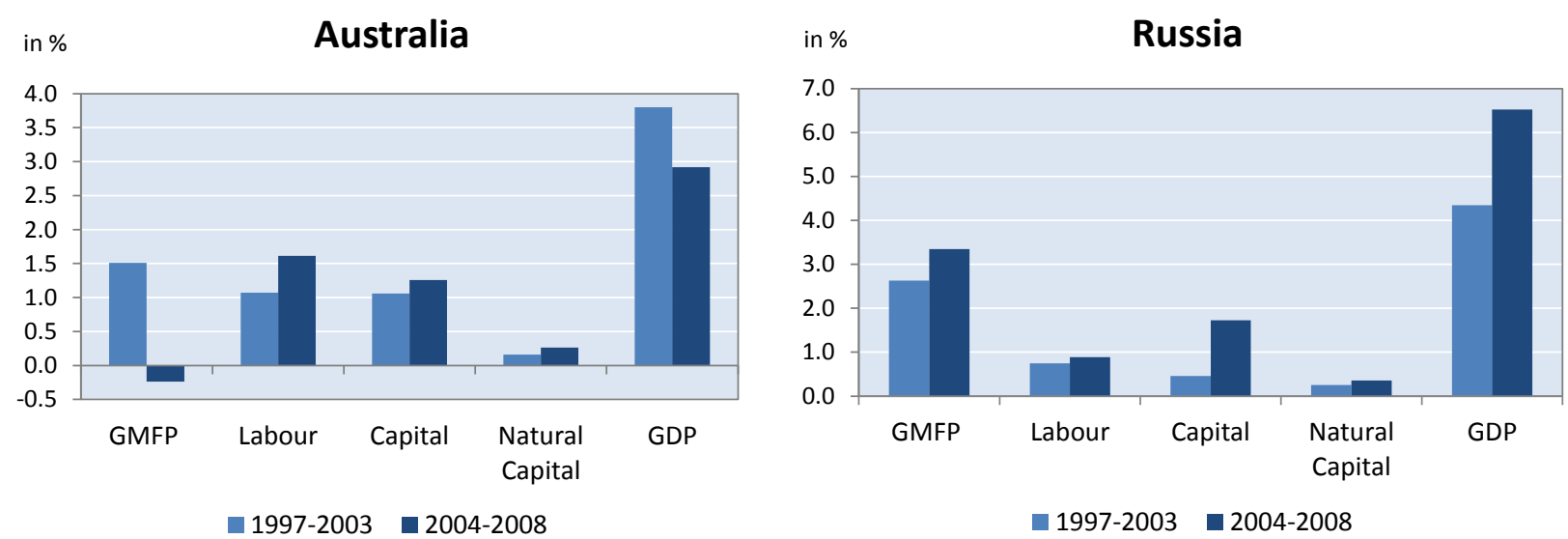

Figure 6. GDP growth and contributions - New Zealand

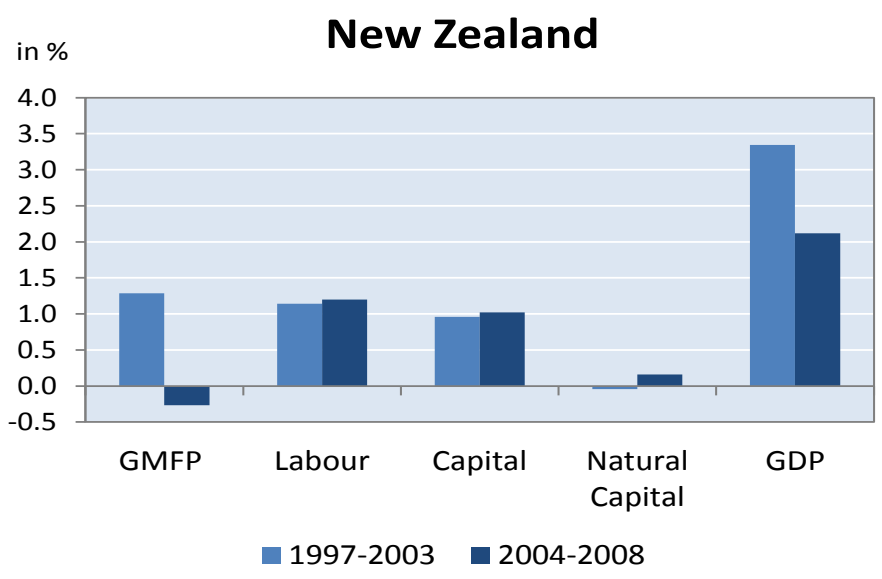

Figure 7. GDP growth and contributions - Mexico and Denmark
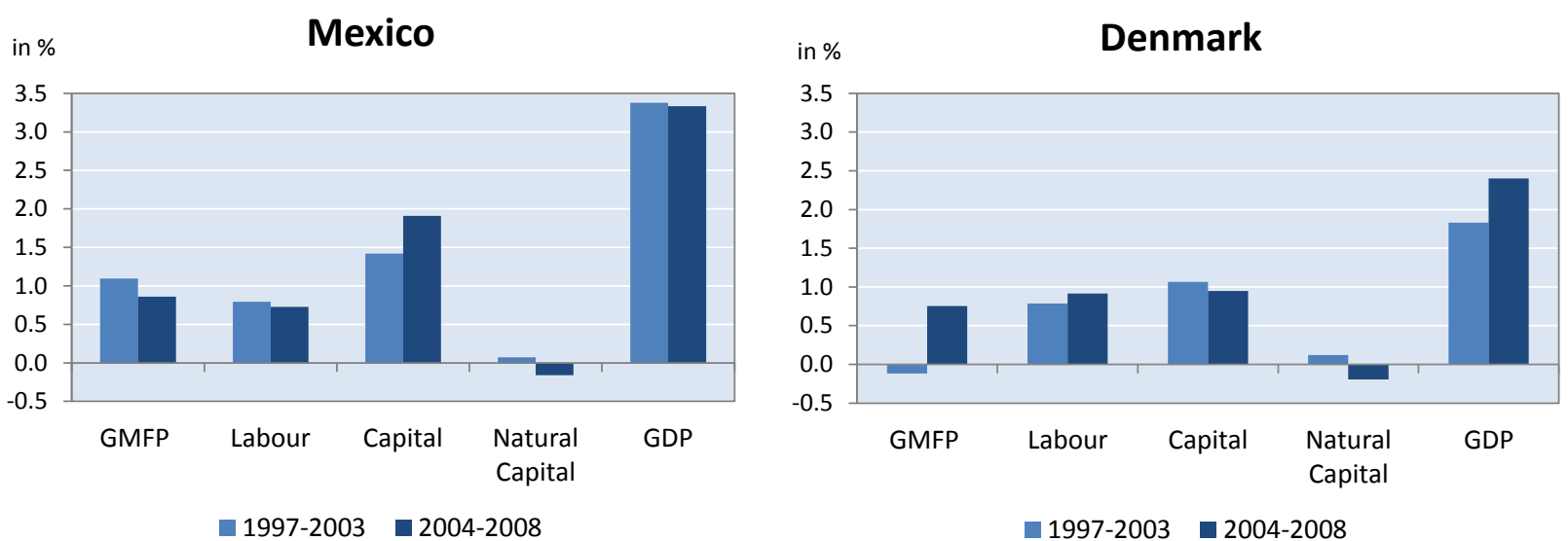